Research Article

\title{
PPV Criterion of a Rock Slope Imbedded with a Fault subjected to Blasting P-Waves
}

\author{
Shiwei Lu $\mathbb{D}^{1,2}$ Chuanbo Zhou, ${ }^{2}$ Zhen Zhang, ${ }^{2}$ Ling Ji, ${ }^{2}$ and Nan Jiang ${ }^{2}$ \\ ${ }^{1}$ School of Urban Construction, Yangtze University, No. 1 Nanhuan Road, Jingzhou 434023, Hubei, China \\ ${ }^{2}$ Faculty of Engineering, China University of Geosciences, No. 388 Lumo Road, Wuhan 430074, Hubei, China \\ Correspondence should be addressed to Shiwei Lu; lushiwei364@163.com
}

Received 31 May 2020; Accepted 4 September 2020; Published 15 September 2020

Academic Editor: Franck Poisson

Copyright (c) 2020 Shiwei Lu et al. This is an open access article distributed under the Creative Commons Attribution License, which permits unrestricted use, distribution, and reproduction in any medium, provided the original work is properly cited.

The open-pit mining slopes continue to become higher and steeper with the continuous exploitation of near-surface mineral resources. The blasting excavation exerts a significance influence on the slope stability. In fact, intact rock slopes do not exist and slope stability is controlled by the geological defects. In this paper, the stability of a rock slope imbedded with a fault is considered. The P-wave component of blasting seismic waves is focused on and the fault is simplified as a semi-infinite crack. In background of Daye iron mine, the peak particle velocity (PPV) threshold is determined based on the linear elastic fracture dynamics. The influence of frequency, Young's modulus, and Poisson's ratio is studied to modify the PPV threshold. Results show that (1) the PPV threshold decreases with the increasing Young's modulus and Poisson's ratio, but increases with the increasing frequency; (2) the initiation angle is immune to Young's modulus and the frequency, and only depends on the Poisson's ratio; (3) the PPV criterion is finally determined as $1.47 \mathrm{~cm} / \mathrm{s}$ when the frequency $f \leq 10 \mathrm{~Hz}, 1.47 \mathrm{~cm} / \mathrm{s}-3.30 \mathrm{~cm} / \mathrm{s}$ when $10 \mathrm{~Hz}<f \leq 50 \mathrm{~Hz}$ and $3.37 \mathrm{~cm} /$ $\mathrm{s}-6.59 \mathrm{~cm} / \mathrm{s}$ when $f>50 \mathrm{~Hz}$, which are far less than that of intact rock slopes; (4) The north slope is quite safe if the proposed PPV threshold is not violated due to the variation range of the initiation angle $\theta_{0}$.

\section{Introduction}

With the continuous exploitation of near-surface mineral resources in China, the open-pit mining slopes continue to become higher and steeper, whose stability is declining [1]. Due to depletion, underground mining will be adopted in more and more mines. As the necessary means in mining, rock excavation, and other constructions, blasting brings huge benefits; on the other hand, blasting-induced geological disasters are nothing new across the world [2].

Dynamic stability has been extensively studied around the world. Ausilioe et al. studied the dynamic stability of reinforced slopes by considering different failure modes $[3,4]$. Li et al. studied the dynamic stability of a rock slope based the Hoek-Brown failure criterion [5]. Chen et al. proposed the equivalent acceleration and Sarma method to analyze the dynamic stability of a rock slope in Jinping I hydropower station [6,7]. Numerical simulation is a powerful method to analyze and evaluate the slope stability.
Deb et al. studied the dynamic stability of the rock slope in Pasir coal mine based the finite element method and in-situ vibration tests [8]. Morales-Esteban et al. studied the stability of the San Pedro cliff at the Alhambra in Granada, Spain, based on the finite element method [9]. Kumar et al. [10] analyzed the stability of rock slopes under the impact of underground blasting by the finite difference method. Zheng et al. [11] adopted the discrete element method and the strength reduction method to analyze the stability of the slope in an iron mine. Liu et al. [12] adopted the discontinuous deformation analysis method to evaluate the slope stability under bench blasting. Cui et al. [13, 14] adopted the particle flow to simulate the failure process of pit slopes.

In fact, intact rock slopes do not exist. All the slopes contain geological defects, such as fault, potential sliding surface. Consequently, the slope stability is controlled by these geological defects. Some but insufficient studies on slope stability have been carried out in the recent years. Ouyang et al. [15] constructed a similar laboratory slope 
model and discussed the influence of weak layers on slope stability subjected to a single borehole basting. Huang and $\mathrm{Wu}$ [16] derived the formula of slope stability factor under the incidence of blasting waves and discussed the influence of duration and dominant frequency.

In blasting engineering, the peak particle velocity (PPV) is always selected as the index for the dynamic stability of rock slopes [17-24]. In general, blasting seismic waves consist of body waves (including P- and S-waves) and surface waves. Both body and surface waves exert a significant influence on the fault. Because the tip of fault is always deeply buried, we can focus on the interaction between body waves and the fault tip and neglect the influence of surface waves. Consequently, the fault can be simplified as semi-infinite crack and the blasting P-wave is selected to study the interaction based on the dynamic fracture mechanics in this paper. The formula of PPV threshold is derived to evaluate slope stability. In background on Daye iron mine, the PPV threshold is proposed.

\section{Interaction of $\mathbf{P}$-Wave and Fault}

2.1. The Simplified Model. A right-handed Cartesian coordinate system Oxy is established, as shown in Figure 1. We suppose that a semi-infinite crack occupies the negative $x$ axis and the crack tip is at the original point. A time-harmonic plane $\mathrm{P}$-wave impinges on the crack. The incident angle is denoted as $\gamma_{1}$. In order to analyze the stress field near the crack tip, a polar coordinate system $(r, \theta)$ is also set up. The potential function of the time-harmonic plane $\mathrm{P}$-wave can be expressed in terms of the displacement potential as

$$
\varphi^{(i)}(x, y, t)=\varphi_{0} e^{-i\left[\alpha_{1}\left(x \cos \gamma_{1}+y \sin \gamma_{1}\right)+\omega t\right]},
$$

where $\varphi_{0}$ is the amplitude of the incident P-wave, $\alpha_{1}$ is the wave number of $\mathrm{P}$-waves and $\alpha_{1}=\left(w / c_{1}\right), \omega$ is the circular frequency of incident wave, $c_{1}$ is the wave speed of P-waves and $c_{1}=\sqrt{(\lambda+2 \mu) / \rho}, \lambda$ and $\mu$ are Lame's constants, $\rho$ is the density of rock mass, and $i$ is the unit of complex.

In general, when the plane P-wave arrives at the crack, two diffracted waves will be generated. They are the diffracted P-wave $\varphi^{(d)}$ and the diffracted SV-wave $\psi^{(d)}$. Let $\varphi$ denote the linear sum of the potentials of the incident $\mathrm{P}$-wave and the diffracted $\mathrm{P}$-wave and $\psi$ denote the linear sum of the potential of the diffracted SV-wave, then

$$
\left\{\begin{array}{l}
\varphi(x, y, t)=\varphi^{(i)}(x, y, t)+\varphi^{(d)}(x, y, t), \\
\psi(x, y, t)=\psi^{(d)}(x, y, t)
\end{array}\right.
$$

where the diffracted field must satisfy the condition $\varphi^{(d)}$, $\psi^{(d)} \longrightarrow 0$ as $\left(x^{2}+y^{2}\right)^{1 / 2} \longrightarrow \infty$.

$$
\left\{\begin{array}{l}
\nabla^{2} \varphi=\frac{1}{c_{1}^{2}} \frac{\partial^{2} \varphi}{\partial t^{2}}, \\
\nabla^{2} \psi=\frac{1}{c_{2}^{2}} \frac{\partial^{2} \psi}{\partial t^{2}},
\end{array}\right.
$$

where $c_{2}$ is the wave speed of SV-waves and $c_{2}=\sqrt{(\mu / \rho)}$.

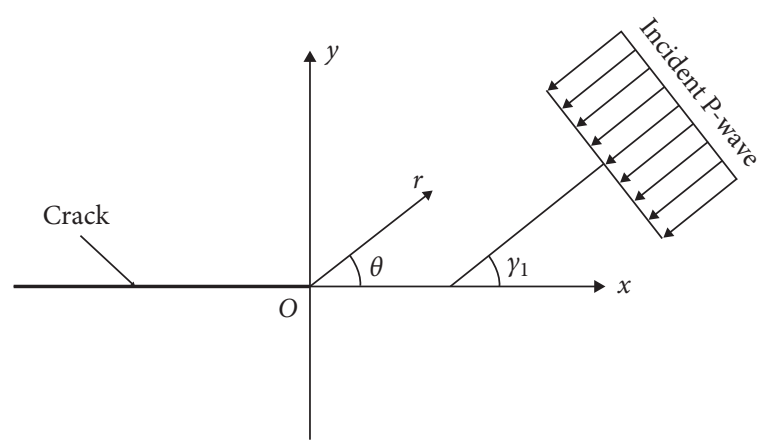

Figure 1: Interaction between P-wave and fault.

$$
\left\{\begin{array}{l}
u_{x}=\frac{\partial \varphi}{\partial x}+\frac{\partial \psi}{\partial y} \\
u_{y}=\frac{\partial \varphi}{\partial y}-\frac{\partial \psi}{\partial x} \\
\sigma_{x x}=\lambda \nabla^{2} \varphi+2 \mu\left(\frac{\partial^{2} \varphi}{\partial x^{2}}+\frac{\partial^{2} \psi}{\partial x \partial y}\right) \\
\sigma_{y y}=\lambda \nabla^{2} \varphi+2 \mu\left(\frac{\partial^{2} \varphi}{\partial y^{2}}-\frac{\partial^{2} \psi}{\partial x \partial y}\right) \\
\sigma_{x y}=\mu\left(2 \frac{\partial^{2} \varphi}{\partial x \partial y}-\frac{\partial^{2} \psi}{\partial x^{2}}+\frac{\partial^{2} \psi}{\partial y^{2}}\right)
\end{array}\right.
$$

Due to that the incident $\mathrm{P}$-wave is time-harmonic, the diffracted waves should be time-harmonic. Then the potentials of diffracted waves can be expressed as

$$
\left\{\begin{array}{l}
\varphi^{(d)}(x, y, t)=\widehat{\varphi}^{(d)}(x, y) e^{-i \omega t}, \\
\psi^{(d)}(x, y, t)=\widehat{\psi}^{(d)}(x, y) e^{-i \omega t},
\end{array}\right.
$$

where $\widehat{\varphi}^{(d)}(x, y)$ and $\widehat{\psi}^{(d)}(x, y)$ are governed by the following Helmholtz equations:

$$
\left\{\begin{array}{l}
\left(\nabla^{2}+\alpha_{1}^{2}\right) \widehat{\varphi}^{(d)}(x, y)=0, \\
\left(\nabla^{2}+\alpha_{2}^{2}\right) \widehat{\psi}^{(d)}(x, y)=0 .
\end{array}\right.
$$

The boundary condition on the crack can be written as:

$$
\left\{\begin{array}{l}
\sigma_{y y}^{(i)}(x, 0, t)+\sigma_{y y}^{(d)}(x, 0, t)=0, \\
\sigma_{x y}^{(i)}(x, 0, t)+\sigma_{y y}^{(d)}(x, 0, t)=0 .
\end{array} \quad x<0 .\right.
$$

Since $\sigma_{y y}^{(i)}$ and $\sigma_{x y}^{(i)}$ are known, the boundary conditions are only a problem for diffracted waves. In order to facilitate the analysis, the problem can be divided into a symmetric part about the $x$-axis and the antisymmetric part. As a consequence, the diffracted filed is divided into two parts: $\varphi^{(s)}, \psi^{(s)}$ is symmetric about the $x$-axis, and $\varphi^{(a)}, \psi^{(a)}$ is antisymmetric. Then the corresponding boundary conditions are 


$$
\begin{cases}\sigma_{x y}^{(s)}(x, 0, t)=0, u_{y}^{(s)}(x, 0, t)=0, & x>0 \\ \sigma_{y y}^{(i)}(x, 0, t)+\sigma_{y y}^{(s)}(x, 0, t)=0, \sigma_{x y}^{(s)}(x, 0, t)=0, & x<0\end{cases}
$$

for the symmetric part and

$$
\begin{cases}\sigma_{y y}^{(a)}(x, 0, t)=0, u_{x}^{(a)}(x, 0, t)=0, & x>0, \\ \sigma_{x y}^{(i)}(x, 0, t)+\sigma_{x y}^{(a)}(x, 0, t)=0, \sigma_{y y}^{(a)}(x, 0, t)=0, & x<0,\end{cases}
$$

for the antisymmetric part. Then the solutions can be expressed as

$$
\left\{\begin{array}{l}
\varphi^{(s)}(x, y, t)=\frac{1}{2 \pi} \int_{-\infty}^{+\infty} A_{11}(s) e^{-\beta_{1}|y|-i s x-i \omega t} \mathrm{~d} s \\
\psi^{(s)}(x, y, t)=\frac{1}{2 \pi} \int_{-\infty}^{+\infty} A_{12}(s) e^{-\beta_{2}|y|-i s x-i \omega t} \mathrm{~d} s \\
\varphi^{(s)}(x, y, t)=\frac{1}{2 \pi} \int_{-\infty}^{+\infty} A_{21}(s) e^{-\beta_{1}|y|-i s x-i \omega t} \mathrm{~d} s \\
\psi^{(s)}(x, y, t)=\frac{1}{2 \pi} \int_{-\infty}^{+\infty} A_{22}(s) e^{-\beta_{2}|y|-i s x-i \omega t} \mathrm{~d} s
\end{array}\right.
$$

where $\beta_{j}=\left\{\begin{array}{ll}\sqrt{s^{2}-\alpha_{j}^{2}} & |s| \geq \alpha_{j} \\ -i \sqrt{\alpha_{j}^{2}-s^{2}} & |s|<\alpha_{j}\end{array}, j=1,2\right.$, the integral path is shown in Figure 2.

$$
\begin{gathered}
\text { Let }\left(\begin{array}{c}
A_{11}(s) \\
A_{12}(s)
\end{array}\right)=\left(2 / \alpha_{2}^{2}\right) A_{1}(s)\left(\begin{array}{c}
s^{2}-(1 / 2) \alpha_{2}^{2} \\
A_{21}(s) \\
A_{22}(s)
\end{array}\right)=\left(2 / \alpha_{2}^{2}\right) A_{2}(s)\left(\begin{array}{c}
i s \beta_{2} \\
s^{2}-(1 / 2) \alpha_{2}^{2}
\end{array}\right) \text {, the boundary }
\end{gathered}
$$

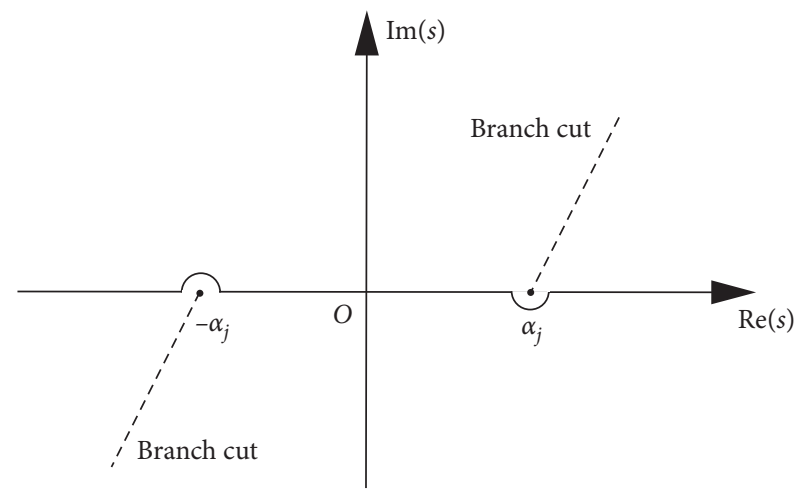

FIgURE 2: Integral path in s-plane.

conditions can be derived as the two following dual integral equations:

$$
\begin{aligned}
& \begin{cases}\frac{1}{2 \pi} \int_{-\infty}^{+\infty} \beta_{1} A_{1}(s) e^{-i s x} \mathrm{~d} s=0, & x>0, \\
\frac{1}{2 \pi} \int_{-\infty}^{+\infty} f(s) A_{1}(s) e^{-i s x} \mathrm{~d} s=P_{1} e^{-i \alpha_{1} x \cos \gamma_{1}}, & x<0,\end{cases} \\
& \begin{cases}\frac{1}{2 \pi} \int_{-\infty}^{+\infty} \beta_{2} A_{2}(s) e^{-i s x} \mathrm{~d} s=0, & x>0, \\
\frac{1}{2 \pi} \int_{-\infty}^{+\infty} f(s) A_{2}(s) e^{-i s x} \mathrm{~d} s=Q_{1} e^{-i \alpha_{1} x \cos \gamma_{1},} & x<0,\end{cases}
\end{aligned}
$$

where $\quad P_{1}=\alpha_{2}^{4} \varphi_{0}\left(1-2 \kappa^{2} \cos ^{2} \gamma_{1}\right), \quad Q_{1}=\kappa^{2} \alpha_{2}^{4} \varphi_{0} \sin 2 \gamma_{1}$, $\kappa=\left(\alpha_{1} / \alpha_{2}\right), f(s)=\left(2 s^{2}-\alpha_{2}^{2}\right)^{2}-4 s^{2} \beta_{1} \beta_{2}$.

Equations (11) and (12) can be solved by the Wiener-Hopf technique $[25,26]$ and the solutions can be expressed as

$$
\left\{\begin{array}{l}
A_{1}(s)=\frac{P_{1}}{2 i} \cdot \frac{\sqrt{\alpha_{1}+\alpha_{1} \cos \gamma_{1}}}{\left(\alpha_{1}^{2}-\alpha_{2}^{2}\right)\left(\alpha_{R}+\alpha_{1} \cos \gamma_{1}\right) F_{+}\left(\alpha_{1} \cos \gamma_{1}\right)} \cdot \frac{1}{\left(s-\alpha_{R}\right)\left(s-\alpha_{1} \cos \gamma_{1}\right) \sqrt{s+\alpha_{1}} F_{-}(s)}, \\
A_{2}(s)=\frac{Q_{1}}{2 i} \cdot \frac{\sqrt{\alpha_{2}+\alpha_{1} \cos \gamma_{1}}}{\left(\alpha_{1}^{2}-\alpha_{2}^{2}\right)\left(\alpha_{R}+\alpha_{1} \cos \gamma_{1}\right) F_{+}\left(\alpha_{1} \cos \gamma_{1}\right)} \cdot \frac{1}{\left(s-\alpha_{R}\right)\left(s-\alpha_{1} \cos \gamma_{1}\right) \sqrt{s+\alpha_{2}} F_{-}(s)},
\end{array}\right.
$$

where $F_{ \pm}(s)=\exp \left\{-(1 / \pi) \int_{\alpha_{1}}^{\alpha_{2}}\right.$ $\left.\arctan \left(\left(4 z^{2} \sqrt{\left(z^{2}-\alpha_{1}^{2}\right)\left(\alpha_{2}^{2}-z^{2}\right)}\right) /\left(2 z^{2}-\alpha_{2}^{2}\right)^{2}\right)(\mathrm{d} z /(z \pm s))\right\}, \alpha_{R}$ is the wave number of Rayleigh wave and given by the minimum positive real root of the equation $\left(\left(2-\alpha_{2}^{2}\right) / \alpha_{R}^{2}\right)^{2}-4 \sqrt{\left(\left(1-\alpha_{1}^{2}\right) / \alpha_{R}^{2}\right)\left(\left(1-\alpha_{2}^{2}\right) / \alpha_{R}^{2}\right)}=0$.

Because the incident wave will not cause the stress concentration near the crack tip, the stress field immediate near the crack tip is only determined by the diffracted waves. With the boundary conditions taken into consideration, the mode I stress intensity factor (SIF) is given by

$$
K_{I}=\lim _{x \longrightarrow 0} \sqrt{2 \pi x} \sigma_{y y}(x, 0, t)=\mu \varphi_{0} \alpha_{2}^{2} \sqrt{\pi \lambda_{1}}\left|K_{I}^{(1)}\right| e^{-i(\omega t+(3 \pi / 4))},
$$

and the mode II SIF is given by 


$$
K_{I I}=\lim _{x \longrightarrow 0} \sqrt{2 \pi x} \sigma_{x y}(x, 0, t)=\mu \varphi_{0} \alpha_{2}^{2} \sqrt{\pi \lambda_{1}}\left|K_{I I}^{(1)}\right| e^{-i(\omega t+(3 \pi / 4))},
$$

where

$K_{I}^{(1)}=\left(\left(\left(1-2 \kappa^{2} \cos ^{2} \gamma_{1}\right) \sqrt{1+\cos \gamma_{1}}\right) /\left(\pi\left(\left(\alpha_{R} / \alpha_{1}\right)+\right.\right.\right.$

$\left.\left.\left.\cos \gamma_{1}\right) F_{+}\left(\alpha_{1} \cos \gamma_{1}\right)\right)\right)$ and $K_{I I}^{(1)}=\left(\left(\kappa^{2} \sin 2 \gamma_{1} \sqrt{\kappa^{-1}+}\right.\right.$ $\left.\left.\cos \gamma_{j}\right) /\left(\pi\left(\left(\alpha_{R} / \alpha_{1}\right)+\cos \gamma_{1}\right) F_{+}\left(\alpha_{1} \cos \gamma_{1}\right)\right)\right)$.

The PPV normal to the wavefront of the incident wave can be expressed as

$$
v_{P}=\kappa \omega \alpha_{2} \varphi_{0} .
$$

Substituting equation (16) into (14) and (15), we can obtain the SIFs in terms of $v_{P}$ as follows:

$$
\begin{aligned}
& K_{I}=\frac{\mu v_{P} \alpha_{2}}{\omega \kappa} \sqrt{\pi \lambda_{1}}\left|K_{I}^{(1)}\right| \mathrm{e}^{-i(\omega t+(3 \pi / 4))}, \\
& K_{I I}=\frac{\mu v_{P} \alpha_{2}}{\omega \kappa} \sqrt{\pi \lambda_{1}}\left|K_{I I}^{(1)}\right| e^{-i(\omega t+(3 \pi / 4))} .
\end{aligned}
$$

2.2. The Safety Criterion Model. The stress field near the crack tip in the polar coordinate system can be expressed as [27]

$$
\left\{\begin{array}{l}
\sigma_{r r}=\frac{1}{2 \sqrt{2 \pi r}}\left[K_{I}(3-\cos \theta) \cos \frac{\theta}{2}+K_{I I}(3 \cos \theta-1) \sin \frac{\theta}{2}\right] \\
\sigma_{\theta \theta}=\frac{1}{2 \sqrt{2 \pi r}} \cos \frac{\theta}{2}\left[K_{I}(1+\cos \theta)-3 K_{I I} \sin \theta\right] \\
\sigma_{r \theta}=\frac{1}{2 \sqrt{2 \pi r}} \cos \frac{\theta}{2}\left[K_{I} \sin \theta+K_{I I}(3 \cos \theta-1)\right]
\end{array}\right.
$$

In fracture mechanics, the maximum circumferential tensile stress criterion is always adopted to analyze fracture cracking. As a consequence, the safety criterion can be expresses as

$$
v_{P}=\frac{2 K_{I C} \omega \kappa}{\mu \alpha_{2} \sqrt{\pi \lambda_{1}} \cos \left(\theta_{0} / 2\right)\left[\left|K_{I}^{(1)}\right|\left(1+\cos \theta_{0}\right)-3 \sin \theta_{0}\left|K_{I I}^{(1)}\right|\right]},
$$

where $\theta_{0}=2 \arctan \left(1-\sqrt{1+8\left(K_{I I} / K_{I}\right)^{2}} /\left(\left(4 K_{I I} / K_{I}\right)\right)\right)$ and $K_{I C}$ is the measured fracture toughness.

\section{Numerical Results and Discussions}

Daye iron mine is located in Hubei Province, China. At its east open pit, the stability of the north slope is controlled by the faults F9 and F9', as shown in Figure 3. The blasting excavation area is between the north and south slopes. According to geological data, the incident angle of blasting waves varies from 0 to $8^{\circ}$ at the tip of $\mathrm{F}^{\prime}$ and from $48^{\circ}$ to $60^{\circ}$ at the tip of F9.

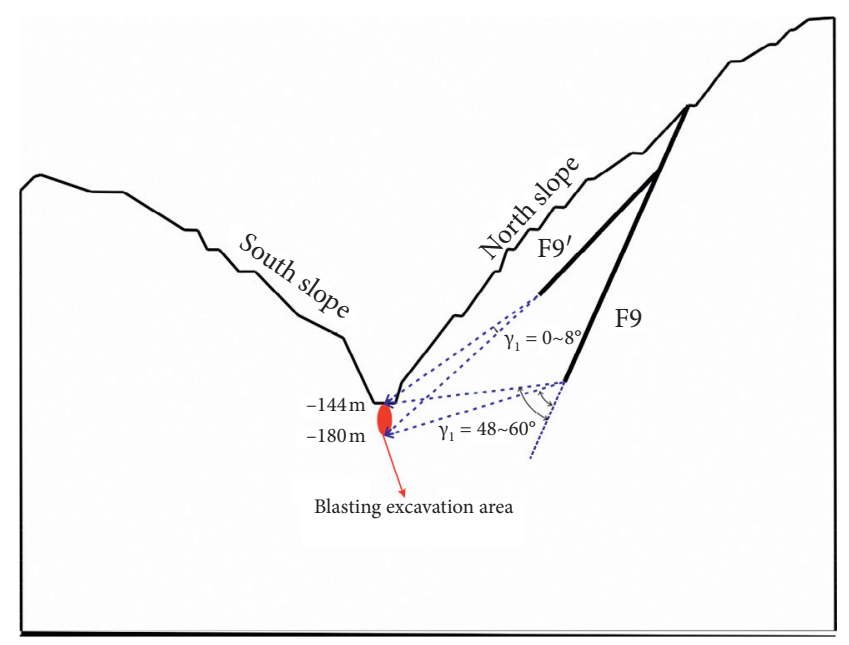

Figure 3: Profit of engineering geological conditions of Daye iron mine.

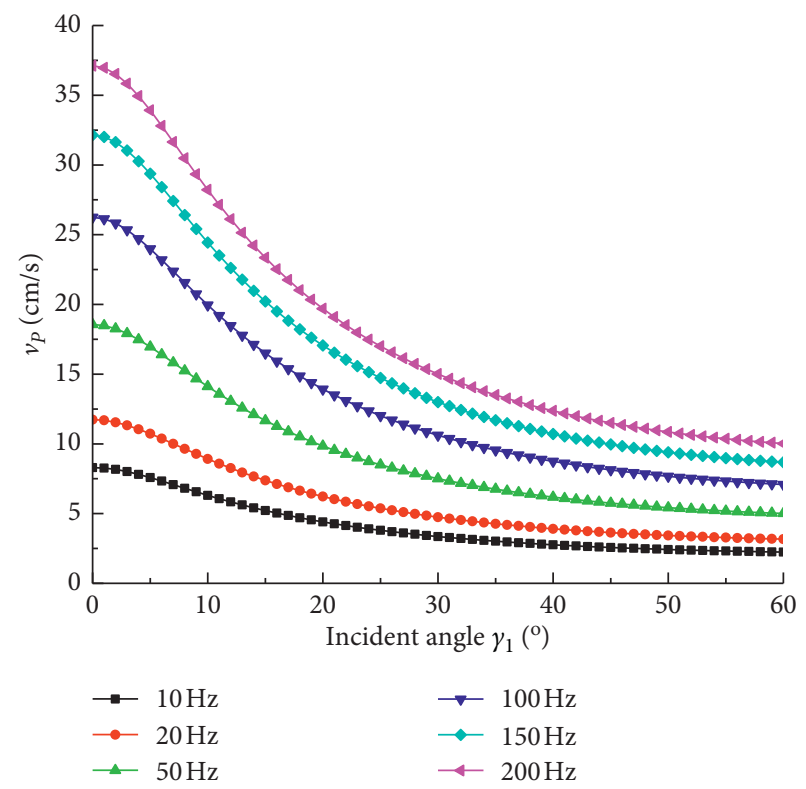

Figure 4: Variation of $v_{P}$ with $\gamma_{1}$ for different $f$.

It is obvious that the PPV threshold $v_{P}$ depends on the mechanical parameters of rock mass and the property of blasting waves. The mode I fracture toughness $K_{I C}$ is measured as $1 \mathrm{MPa} \cdot \mathrm{m}^{1 / 2}$. The parameters are selected as $\rho=2710 \mathrm{~kg} / \mathrm{m}^{3}, v=0.25$. The PPV threshold $v_{P}$ vs. incident angle $\gamma_{1}$ curves are plotted in Figure 4 .

It can be seen from Figure 4 that $v_{P}$ decreases with the increasing incident angle $\gamma_{1}$ for the same $E$ and also decreases with the increasing $E$ for the same $\gamma_{1}$. The least $v_{P}$ occurs when $\gamma_{1}=60^{\circ}$ and it increases from $2.24 \mathrm{~cm} / \mathrm{s}$ to $10.02 \mathrm{~cm} / \mathrm{s}$ when the frequency $f$ increases from $10 \mathrm{~Hz}$ to $200 \mathrm{~Hz}$. Due to the sensitivity, the PPV criterion should be strictly controlled and given in accordance with the variation range of frequency. With the Blasting Safety Regulation (GB6722-2014) in China taken into consideration, the PPV 


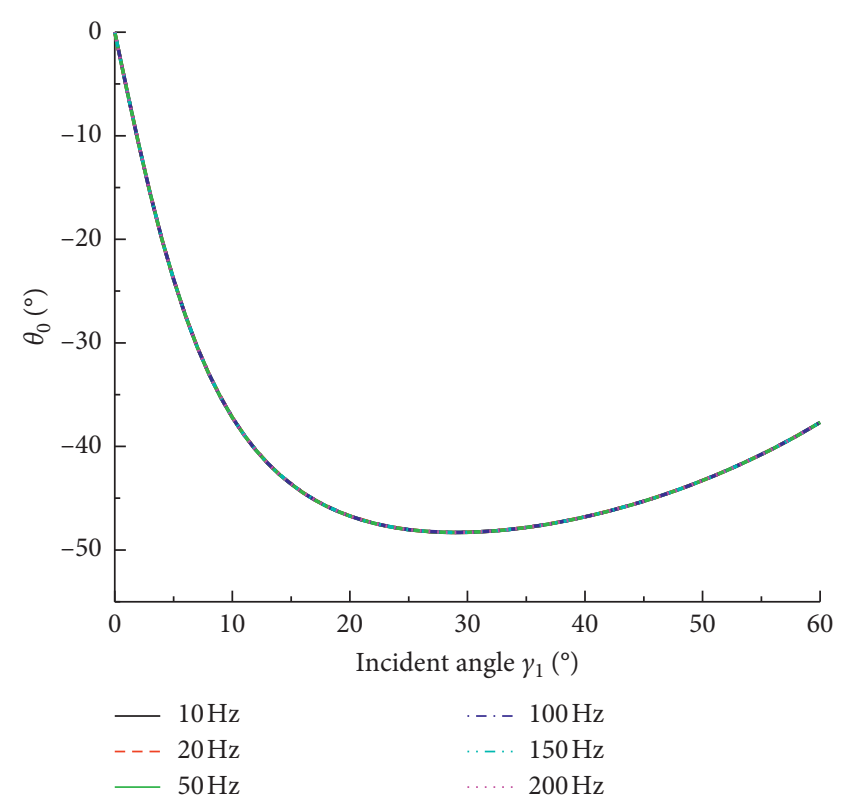

Figure 5: Variation of $\theta_{0}$ with $\gamma_{1}$ for different $f$.

criterion is determined as $2.24 \mathrm{~cm} / \mathrm{s}$ when $f \leq 10 \mathrm{~Hz}, 2.24 \mathrm{~cm} /$ $\mathrm{s}-5.01 \mathrm{~cm} / \mathrm{s}$ when $10 \mathrm{~Hz}<f \leq 50 \mathrm{~Hz}$, and $5.01 \mathrm{~cm} /$ $\mathrm{s}-10.02 \mathrm{~cm} / \mathrm{s}$ when $f>50 \mathrm{~Hz}$.

The variation of the initiation angle $\theta_{0}$ with $\gamma_{1}$ for different frequencies is shown in Figure 5. It can be seen from Figure 5 that the curves totally overlap for different frequencies, indicating that $\theta_{0}$ is immune to $f$. The initiation angle varies from $-48.3^{\circ}$ to $0^{\circ}$ and we can claim that the north slope is quite safe if the proposed PPV threshold is not violated.

In order to get a more general and more applicable threshold, the influence of Young's modulus $E$ and Poisson's ratio $v$ will be discussed.

3.1. The Influence of Young's Modulus. As mentioned before, $v_{P}$ decreases monotonously with increasing $f$. The parameters are selected as $\rho=2710 \mathrm{~kg} / \mathrm{m}^{3}, \nu=0.25$. The variation of $v_{P}$ with $E$ for different $f$ when $\gamma_{1}=60^{\circ}$ is shown in Figure 6 .

It can be seen from Figure 6 that $v_{P}$ decreases monotonously and quickly with the increasing $E$. $v_{P}$ decreases from $5.88 \mathrm{~cm} / \mathrm{s}$ to $1.53 \mathrm{~cm} / \mathrm{s}$ when $E$ increases from $10 \mathrm{GPa}$ to $30 \mathrm{GPa}$ and $f=10 \mathrm{~Hz}, v_{P}$ decreases from $13.14 \mathrm{~cm} / \mathrm{s}$ to $3.43 \mathrm{~cm} / \mathrm{s}$ when $f=50 \mathrm{~Hz}$, and $v_{P}$ decreases from $26.29 \mathrm{~cm} / \mathrm{s}$ to $6.86 \mathrm{~cm} / \mathrm{s}$ when $f=200 \mathrm{~Hz}$. As a consequence, the PPV criterion should be modified as $1.53 \mathrm{~cm} / \mathrm{s}$ when $f \leq 10 \mathrm{~Hz}, 1.53 \mathrm{~cm} / \mathrm{s}-3.43 \mathrm{~cm} / \mathrm{s}$ when $10 \mathrm{~Hz}<f \leq 50 \mathrm{~Hz}$, and $3.43 \mathrm{~cm} / \mathrm{s}-6.86 \mathrm{~cm} / \mathrm{s}$ when $f>50 \mathrm{~Hz}$.

The variation of the initiation angle $\theta_{0}$ with $\gamma_{1}$ for different $E$ when $f=10 \mathrm{~Hz}$ is shown in Figure 7. It can be seen from Figure 7 that $\theta_{0}$ is immune to $E$. The initiation angle still varies from $-48.3^{\circ}$ to $0^{\circ}$, and we can claim that the north slope is quite safe if the proposed PPV threshold is not violated.

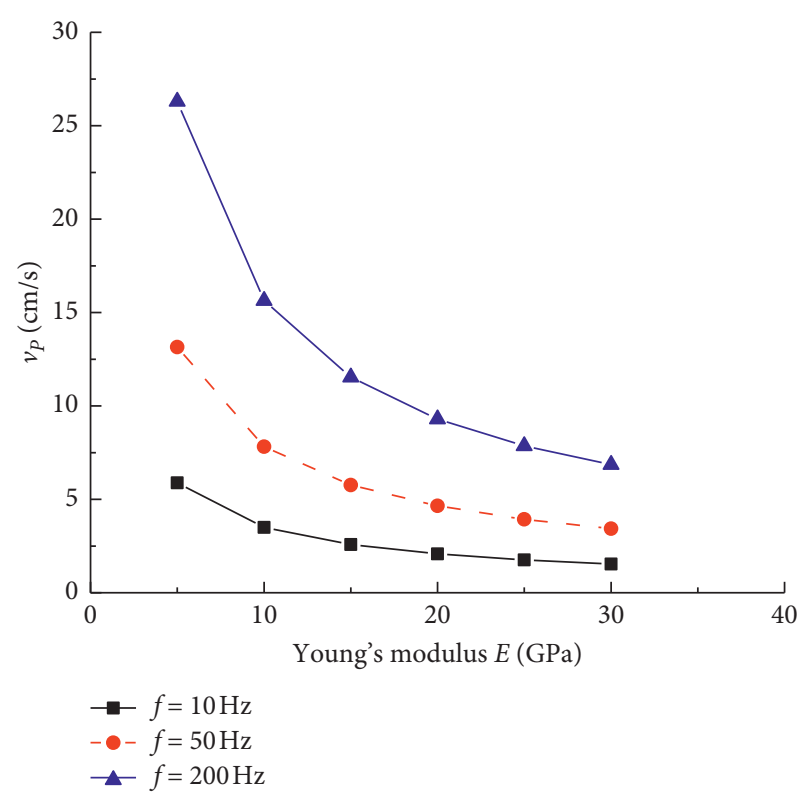

FIGURE 6: Variation of $v_{P}$ with $E$ for different $f$ when $\gamma_{1}=60^{\circ}$ and $v=0.25$.

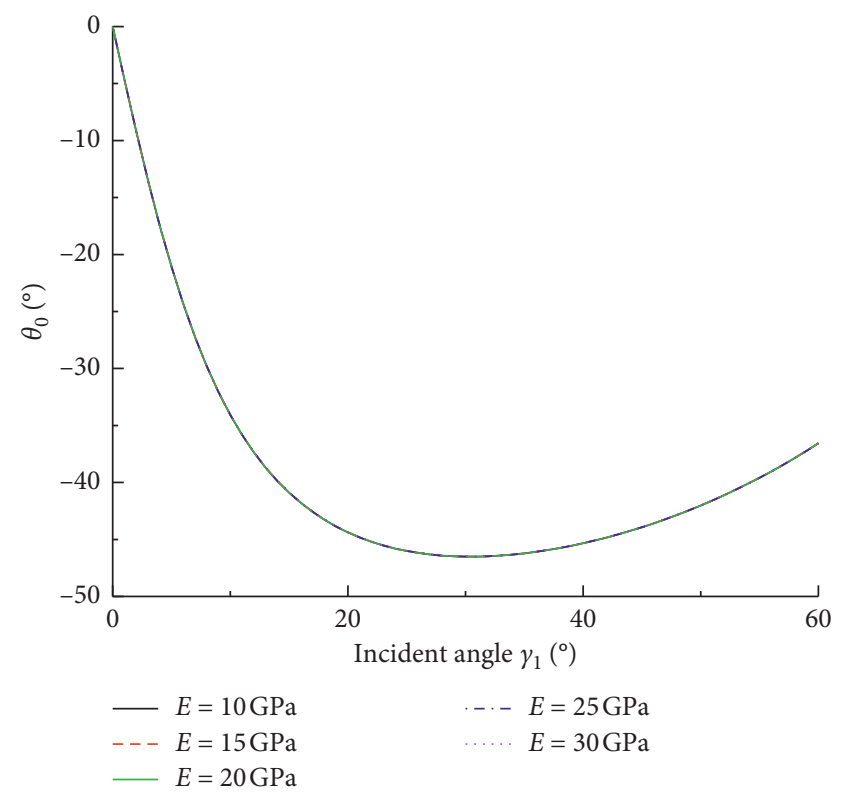

Figure 7: Variation of $\theta_{0}$ with $\gamma_{1}$ for different $E$.

3.2. The Influence of Poisson's Ratio. As mentioned before, $v_{P}$ decreases monotonously with the increasing $E$. For the safety, we choose the parameters as $E=30 \mathrm{GPa}, f=10 \mathrm{~Hz}$, $50 \mathrm{~Hz}$ and $200 \mathrm{~Hz}$. The variation of $v_{P}$ with Poisson's ratio $v$ for different frequencies is shown in Figure 8.

It can be seen from Figure 8 that $v_{P}$ decreases monotonously and slowly with the increasing $v \cdot v_{P}$ decreases from $1.59 \mathrm{~cm} / \mathrm{s}$ to $1.47 \mathrm{~cm} / \mathrm{s}$ when $v$ increases from 0.10 to 0.30 and $f=10 \mathrm{~Hz}, v_{P}$ decreases from $3.57 \mathrm{~cm} / \mathrm{s}$ to $3.30 \mathrm{~cm} / \mathrm{s}$ when $f=50 \mathrm{~Hz}$, and $v_{P}$ decreases from $7.15 \mathrm{~cm} / \mathrm{s}$ to $6.59 \mathrm{~cm} / \mathrm{s}$ when $f=200 \mathrm{~Hz}$. As a consequence, the PPV criterion should be modified as $1.47 \mathrm{~cm} / \mathrm{s}$ when $f \leq 10 \mathrm{~Hz}, 1.47 \mathrm{~cm} / \mathrm{s}-3.30 \mathrm{~cm} / \mathrm{s}$ 


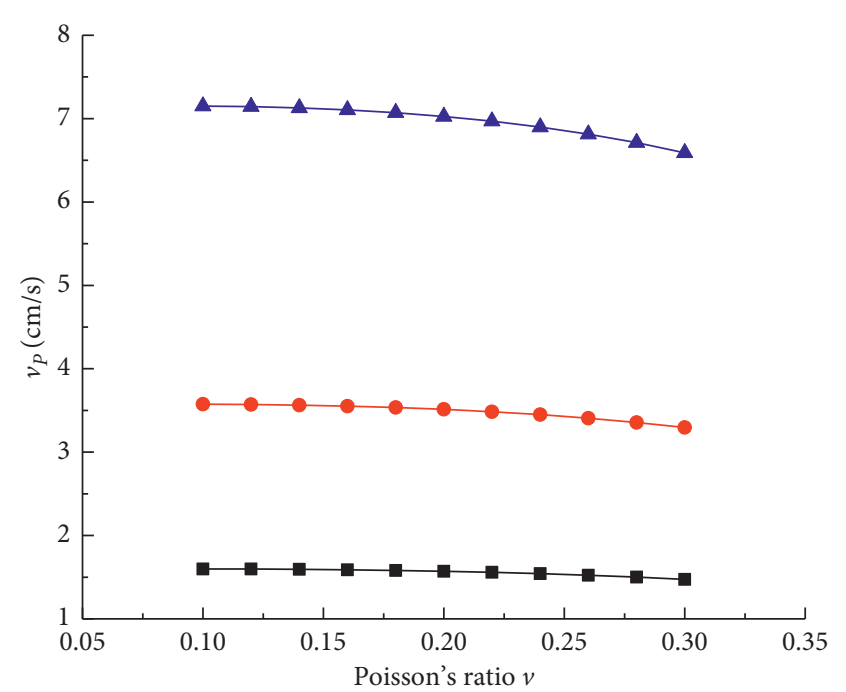

$\rightarrow-f=10 \mathrm{~Hz}$
$\longrightarrow f=50 \mathrm{~Hz}$
$\neg f=200 \mathrm{~Hz}$

Figure 8: Variation of $v_{P}$ with $v$ for different $f$ when $\gamma_{1}=60^{\circ}$ and $E=30 \mathrm{GPa}$.

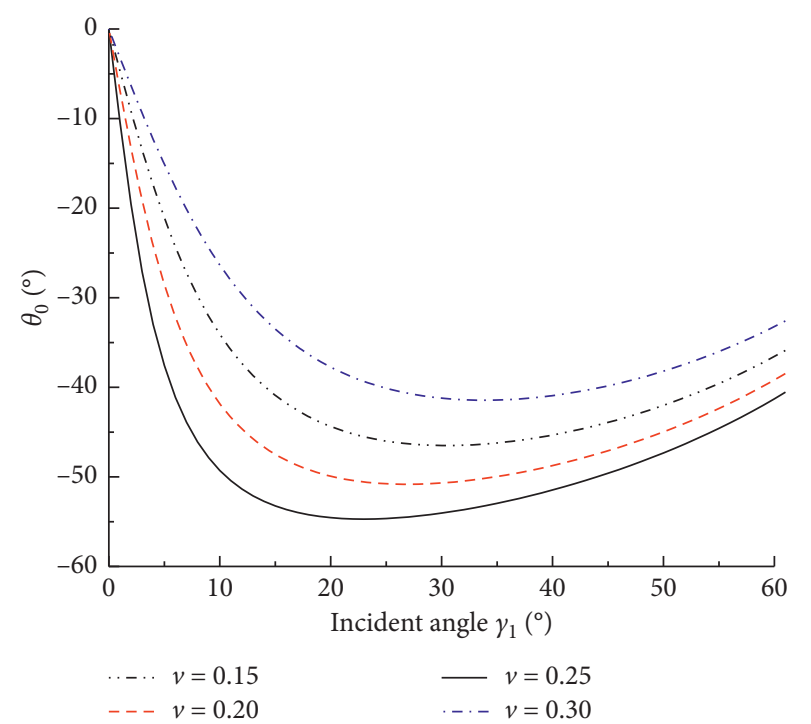

Figure 9: Variation of $\theta_{0}$ with $\gamma_{1}$ for different $v$.

when $10 \mathrm{~Hz}<f \leq 50 \mathrm{~Hz}$, and $3.37 \mathrm{~cm} / \mathrm{s}-6.59 \mathrm{~cm} / \mathrm{s}$ when $f>50 \mathrm{~Hz}$.

The variation of the initiation angle $\theta_{0}$ with $\gamma_{1}$ for different $E$ when $f=10 \mathrm{~Hz}$ is shown in Figure 9. It can be seen from Figure 9 that $\theta_{0}$ changes obviously with the increasing $v$. The maximum $\theta_{0}$ varies from $-54.7^{\circ}$ to $-39.3^{\circ}$. Although the variation range of $\theta_{0}$ narrows, no positive $\theta_{0}$ occurs and we can claim that the north slope is quite safe if the proposed PPV threshold is not violated.

\section{Conclusions}

The following conclusions can be drawn:
(1) The PPV threshold decreases with the increasing Young's modulus $E$ and the Poisson's ratio $v$, but increases with the increasing frequency $f$.

(2) The initiation angle $\theta_{0}$ is immune to Young's modulus $E$ and the frequency $f$ and only depends on Poisson's ratio $v$.

(3) The PPV criterion is finally determined as $1.47 \mathrm{~cm} / \mathrm{s}$ when $f \leq 10 \mathrm{~Hz}, \quad 1.47 \mathrm{~cm} / \mathrm{s}-3.30 \mathrm{~cm} / \mathrm{s}$ when $10 \mathrm{~Hz}<f \leq 50 \mathrm{~Hz}$, and $3.37 \mathrm{~cm} / \mathrm{s}-6.59 \mathrm{~cm} / \mathrm{s}$ when $f>50 \mathrm{~Hz}$, which are far less than that of intact rock slopes.

(4) The north slope is quite safe if the proposed PPV threshold is not violated due to the variation range of the initiation angle $\theta_{0}$.

\section{Data Availability}

The data used to support the findings of this study are included within the article.

\section{Conflicts of Interest}

The authors declare that there are no conflicts of interest regarding the publication of this article.

\section{Acknowledgments}

This work was supported by the Hubei Natural Science Foundation Project (Grant no. 2019CFB224), the scientific research project of Hubei Provincial Department of Education (Grant no. Q20191308), and the Jingzhou Science and Technology Project (Grant no. 2019Z18001). These grants are gratefully acknowledged.

\section{References}

[1] X. Wu, Q. Guo, and Y. Zhang, "A new mathematical model for predicting the surface vibration velocity on the step topography," Shock and Vibration, vol. 2018, Article ID 8356254, 8 pages, 2018.

[2] X. Shi, X. Qiu, J. Zhou, H. Dan, C. Xin, and G. Yonggang, "A comparative study of ground and underground vibrations induced by bench blasting," Shock and Vibration, vol. 2016, Article ID 2, 9 pages, 2016.

[3] E. Ausilio, E. Conte, and G. Dente, "Seismic stability analysis of reinforced slopes," Soil Dynamics and Earthquake Engineering, vol. 19, no. 3, pp. 159-172, 2000.

[4] B. M. Basha and P. K. Basudhar, "Pseudo static seismic stability analysis of reinforced soil structures," Geotechnical and Geological Engineering, vol. 28, no. 6, pp. 745-762, 2010.

[5] A. J. Li, A. V. Lyamin, and R. S. Merifield, "Seismic rock slope stability charts based on limit analysis methods," Computers and Geotechnics, vol. 36, no. 1-2, pp. 135-148, 2009.

[6] M. Chen, W. Lu, P. Yan, and C. Zhou, "New method for dynamic stability analysis of rock slope under blasting vibration based on equivalent acceleration and Sarma method," Canadian Geotechnical Journal, vol. 51, no. 4, pp. 441-448, 2014.

[7] M. Chen, W. Lu, C. Zhou, D. Shu, and H. Xu, "Rock slope stability under blasting vibration based on equivalent 
acceleration," Explosion and Shock Waves, vol. 31, pp. 475480, 2011.

[8] D. Deb, K. N. R. Kaushik, B. H. Choi, C. H. Ryu, Y. B. Jung, and C. Sunwoo, "Stability assessment of a pit slope under blast loading: a case study of Pasir coal mine," Geotechnical and Geological Engineering, vol. 29, no. 4, pp. 419-429, 2011.

[9] F. Martínez-Álvarez, A. Ryu, J. L. de Justo, J. Reyes, J. Miguel Azañón, and P. Durand, "Stability analysis of a slope subject to real accelerograms by finite elements. Application to San Pedro cliff at the Alhambra in Granada," Soil Dynamics and Earthquake Engineering, vol. 69, pp. 28-45, 2015.

[10] R. Kumar, D. Choudhury, and K. Bhargava, "Simulation of rock subjected to underground blast using FLAC3D," Japanese Geotechnical Society Special Publication, vol. 2, no. 12, pp. 508-511, 2016.

[11] Y. Zheng, C. Chen, X. Zhu et al., "Node quasi-static stability analysis of rock slope under excavation blasting based on UDEC Chinese," Journal of Rock Mechanics and Engineering, vol. 33, pp. 3932-3940, 2014.

[12] Y. Liu, J. Yang, and D. Yu, "Study on simulation of discontinuous deformation analysis for slope stability under blast impact," Acta Armamentar II, vol. 31, pp. 74-78, 2010.

[13] T. Cui, Y. Ma, and L. Wang, "Blasting process simulation and stability study of an open mine slope based on PFC3D," Applied Mathematics and Mechanics, vol. 35, pp. 759-767, 2014.

[14] T. Cui, Y. Ma, and L. Wang, "Simulation and analysis of earthquake stability for open-pit coal mine slope with complex structural surface," Earthquake Engineering and Engineering Dynamics, vol. 36, pp. 200-206, 2016.

[15] J. Ouyang, S. Zheng, J. Zhang, X. Guo, Z. Xiao, and X. Song, "Test study on influence of blast effect on stability of bedding rock slope with wek interlayer," Blasting, vol. 26, pp. 10-14, 2009.

[16] Z. Huang and L. Wu, "Efffect of blasting vibration on stability of beeding rock slope at tuunel entrance," Blasting, vol. 29, pp. 110-114, 2012.

[17] Z. Mingsheng, H. Dong, C. Maosen, C. En-an, L. Jun, and K. Qiang, "An energy-based safety evaluation index of blast vibration," Shock and Vibration, vol. 2015, Article ID 698193, 9 pages, 2015.

[18] M. Chen, W. Lu, L. Wu, and H. Xu, "Safety threshold of blasting vibtation velocity to high rock slope of Xiaowan hydropower station Chinese," Journal of Rock Mechanics and Engineering, vol. 26, pp. 51-56, 2007.

[19] N. Jiang, C. Zhou, S. Lu, and Z. Zhang, "Propagation and prediction of blasting vibration on slope in an open pit during underground mining," Tunnelling and Underground Space Technology, vol. 70, pp. 409-421, 2017.

[20] N. Jiang, C. Zhou, S. Lu, and Z. Zhang, "Effect of underground mine blast vibrations on overlaying open pit slopes: a case study for daye iron mine in China," Geotechnical and Geological Engineering, vol. 36, no. 3, pp. 1475-1489, 2018.

[21] M. Liu, C. Wu, and Z. Zhang, "Experimentation on judging standard of blasting vibration safety in high slope excavation of Xiaowan hydropower station," Journal of Yangtze River Science Research Institute, vol. 24, pp. 51-56, 2007.

[22] M. Li, L. Kemin, X. Shuangshuang, D. Xiaohua, and C. Sydney, "Research on effects of blast casting vibration and vibration absorption of presplitting blasting in open cast mine," Shock and Vibration, vol. 2016, Article ID 4091732, 9 pages, 2016.

[23] S. Lu, C. Zhou, Z. Zhang, and N. Jiang, "Particle velocity response of surrounding rock of a circular tunnel subjected to cylindrical P-waves," Tunnelling and Underground Space Technology, vol. 83, pp. 393-400, 2019.

[24] Q. Wu, J. Zhang, X. Cao, and Y. Chen, "Test and study of lamination effect caused by blasting of cutting slope in layered rock masses China Railway," Science, vol. 25, pp. 50-54, 2004.

[25] V. G. Daniele and R. S. Zich, The Wiener-Hopf Method in Electromagnetics, SciTech Publishing, Raleigh, NC, USA, 2014.

[26] B. Noble, Methods Based on the Wiener-Hopf Technique for the Solution of Partial Differential Equations, Pergamon Press, New York, NY, USA, 1958.

[27] S. Li, T. He, and X. Ying, Rock Facture Mechanics, Science Press, Beijing, China, 2016. 